Éducation

et sociétés

plurilingues

\section{Éducation et sociétés plurilingues}

37 | 2014

Varia

\title{
Avanzar en la práctica de la docencia
}

Reflexión sobre un itinerario intelectual

Isabel Vazquez de Castro

\section{(2) OpenEdition}

\section{Journals}

Edición electrónica

URL: http://journals.openedition.org/esp/433

DOI: $10.4000 /$ esp.433

ISSN: 2532-0319

\section{Editor}

Centre d'Information sur l'Éducation Bilingue et Plurilingue

\section{Edición impresa}

Fecha de publicación: 1 diciembre 2014

Paginación: 45-54

ISSN: 1127-266X

Referencia electrónica

Isabel Vazquez de Castro, «Avanzar en la práctica de la docencia », Éducation et sociétés plurilingues [En línea], 37 | 2014, Puesto en línea el 01 octubre 2015, consultado el 15 septiembre 2020. URL : http://journals.openedition.org/esp/433 


\section{AVANZAR EN LA PRÁCTICA DE LA DOCENCIA: REFLEXIÓN SOBRE UN ITINERARIO INTELECTUAL}

\section{Isabel VázQuez de Gastro}

Basandosi sulla sua esperienza personale di ricercatrice e formatrice di futuri professori di spagnolo, l'autrice di quest'articolo in primo luogo dà consigli per realizzare un lavoro di ricerca. In seguito conduce una riflessione sulla didattica dello spagnolo in Francia. Infine spiega l'importanza della Institución Libre de Enseñanza per la didattica dello spagnolo in Francia.

En s'appuyant sur son expérience personnelle en tant que chercheuse et formatrice de futurs professeurs d'espagnol, l'auteure de cet article donne, d'abord, des conseils pour réaliser un travail de recherche. Ensuite, elle apporte une réflexion sur la didactique de l'espagnol en France. Pour finir, elle explique l'importance de la Institución Libre de Enseñanza pour la didactique de l'espagnol en France.

\section{LA REFLEXIÓN SOBRE LA PROPIA PRÁCTICA}

I ntentaré en las líneas que siguen trazar el desarrollo de mi experiencia profesional. Me gustaría con ello animar a los o las colegas que se propongan mejorar su currículo y se pregunten cómo se consigue obtener un estatuto que les permita acompañar el trabajo intelectual de alto nivel de otros investigadores, en particular aquellos que se orientan a redactar y defender una tesis y optar con ello al diploma de tercer ciclo de estudios universitarios o grado de doctor.

La capacitación para dirigir investigaciones en Francia exige un dispositivo semejante al que se aplica a los futuros docentes en su proceso de formación. Siendo desde el año 2002 profesora de docentes o futuros profesores de enseñanza primaria y secundaria del sistema educativo público francés, he reflexionado sobre este tipo de práctica, en particular sobre el proceso de escritura formativa sobre la propia actividad docente. Se trata de redactar, de manera organizada (y si posible, agradable de leer), el recorrido intelectual y profesional que el investigador, ya doctor, ha emprendido desde la defensa de su tesis. Es una actividad reflexiva, de balance y selección de lo hecho para poder comenzar en condición de experiencia significativa y comunicable un nuevo trabajo en el mismo campo y con un nivel superior de reflexión 
Avanzar en la práctica de la docencia: reflexión sobre un itinerario intelectual

I. Vázquez de CAstro contextualizada sobre el tema de estudio.

Como dije antes, en mi actividad profesional intento que los futuros maestros o los futuros profesores de español de la secundaria observen de otros docentes diversas prácticas profesionales; encuentren textos, referencias, ideas o propuestas que convengan a su situación o a su manera de hacer; lean de manera selectiva y crítica para ampliar su conocimiento sobre el tema y experimenten por sí mismos dispositivos originales concebidos como una prolongación del anterior trabajo y reflexión. Todo ello con el fin de construirse del modo más personal y adaptado posible una identidad docente propia.

Mi opinión personal sobre este trabajo de reflexión ha evolucionado bastante. Si bien siempre me parece arduo el discurso argumentativo sobre el propio pensamiento que lo detalla y explica, comprendo su necesidad en un trabajo de investigación para sentar unas bases comprensibles y situadas desde el punto de vista epistemológico. Por otra parte, la búsqueda del principio retórico o hilo rojo sin duda desempeña el oficio de hilo de Ariadna para guiarnos y mostrar el sentido más evidente de la investigación que nos proponemos llevar a cabo. En el laberinto de las múltiples opciones de investigación que son posibles, o que solo serán exploradas de manera más superficial, este hilo nos ayuda a no perder de vista un eje de trabajo. Si bien es un artificio retórico propio de una determinada cultura académica, es también una manera de organizar el pensamiento de una manera eficaz para su posible transmisión o prolongación. Además, lejos de ser un procedimiento exclusivamente académico, este proceso de formalización y abstracción permite un distanciamiento de la propia tarea y una reflexión interesante sobre ella desde un punto de vista diferente.

Me permito aconsejar a los que se lancen a semejantes aventuras que intenten simplificar al máximo en un primer momento su obra escrita, intentando encontrar los elementos fundamentales. Esta primera reflexión ayuda a encontrar los principales ejes de trabajo realizados al cabo de los años. En mi caso, éstos han sido el teatro español (pero no exclusivamente) de los siglos XX y XXI, la didáctica del español, principalmente en Francia como asignatura escolar, y la historia cultural de la España contemporánea, siguiendo principalmente los programas de oposiciones de profesorado de español. Uniendo los dos últimos temas, la enseñanza del español en Francia y la Historia de la Cultura española, se encuentran numerosos elementos de interculturalidad que aparecen en filigrana: los aspectos de la civilización hispánica (histo- 
Avanzar en la práctica de la docencia: reflexión sobre un itinerario intelectual

I. Vázquez de Castro
LA DIDÁCTICA DEL ESPAÑOL EN FRANCIA ria, artes plásticas, literatura) que más van a interesar en Francia para la enseñanza del español en un ámbito académico y, posteriormente, escolar. Así he podido profundizar en los temas que van a ser a su vez estudiados para la preparación de las oposiciones por los futuros docentes. Se trata de estudios innovadores transnacionales, europeos y mundiales que se declinan muchas veces en un rico diálogo cultural franco-español. La cultura en sus vertientes histórica, artística, etnológica o sociológica se interrelaciona en una inter(re)ferencia o interferencia como estudia actualmente mi grupo de investigación IMAGER de la Universidad de ParisEst.

Poco a poco, cada pieza de un puzle, que parecía irresoluble por su aparente diversidad, va encontrando su sitio: lo que en un principio se nos antojaba caótico y sin sentido, tras este trabajo de estructuración se convierte en algo evidente. No sabré determinar si se trata de una manifestación del logos creador, de fenómenos de enunciación que crean un sentido al expresarse o que sin tener nosotros conciencia precisa de lo que hacemos, nuestro motor intelectual va siguiendo un camino más lógico de lo que podría parecer a simple vista. Sin duda, se puede llegar a alcanzar una forma más compleja y superior de pensamiento que nos mejora, no sólo a través de la experiencia sino, sobre todo, gracias a lo que de ella estamos dispuestos a aprender: la antigüedad o los méritos que acompañan el paso del tiempo son sin duda formativos, pero no siempre.

En mi caso, esta evidencia inicial de lo que era central en mi práctica profesional era la enseñanza del español en Francia. Es eso lo que he hecho fundamentalmente desde 1979, lo que quiero seguir haciendo y lo que me interesa ahora como proyecto científico y hasta artístico, acompañando la práctica de la escena y de la escritura dramática con la enseñanza del idioma desde el año 2013.

No soy pionera en este tipo de metodología pues es frecuente encontrar experiencias docentes en las que particularmente el español como disciplina se asocia en Francia a otras actividades artísticas: teatro, creación de textos, crítica de producciones artísticas diversas de naturaleza plástica, literaria, cinematográfica, de participación en eventos...

Por ello no es de extrañar que el núcleo central de mi actividad docente se vea acompañada por una actividad de investigación que la nutre y alimenta. Si mi especialidad de origen era el teatro del siglo XX y su renovación a través de la reescritura de un tea- 
Avanzar en la práctica de la docencia: reflexión sobre un itinerario intelectual

I. Vázquez de CAstro tro popular muy característico y aparentemente pobre, como se ha considerado a menudo al teatro de títeres, no tardé en establecer numerosos lazos con temáticas asociadas a los siete autores estudiados y a los lazos entre la cultura popular y la cultura creada por artistas consagrados y reconocidos, como fueron en su tiempo y hasta ahora, aunque con desigual fortuna, los dramaturgos estudiados. La historia cultural, inserta en el conjunto de la civilización hispánica, se entiende en un sentido amplio que abarca la historia de las ideas y su difusión así como las principales prácticas de transmisión cultural: espectáculos, literaturas, enseñanza, tradición oral...

El punto de vista elegido fue de índole práctica, privilegiando en principio los temas elegidos para la preparación de las oposiciones para la cátedra de secundaria (CAPES) o de integración en la Universidad (Agrégation para los profesores titulares del CAPES) que a pesar de sus estatutos diferentes comparten situaciones docentes muy similares, cuando no idénticas. Pero con la perspectiva de los años vemos que estos temas o "cuestiones" para las oposiciones que se renuevan cada dos años en principio, conservando uno del año anterior y cambiando al menos otro, tienen entre sí una coherencia y constituyen un objeto de estudio interesante. En el campo de la educación comparada, las resistencias y tensiones, en torno a los cambios introducidos y en vías de introducción para estrechar los lazos entre la investigación y la docencia a través de la profundización de los programas de estudios en la enseñanza secundaria y primaria, han sido también un objeto de reflexión permanente.

El apoyo institucional a estas interrelaciones entre las investigaciones de alto nivel que merecen ser difundidas supone también que los docentes de idiomas en el curso de su formación hayan tenido acceso a una experiencia formativa de investigación en la enseñanza superior. Por una parte es transmisiva: hay cours magistraux que acompañan como conferencias de excelencia la presentación de las obras estudiadas o los temas de civilización que deben preparar; por otra parte se inicia a los futuros docentes de primaria y secundaria en una metodología reflexiva, con una orientación profesional para los que optan por la vía de la docencia en la enseñanza secundaria o primaria, para las que se exige un nivel de Máster, o con una orientación de investigación universitaria sobre una disciplina específica que desembocará tras un Máster adecuado, en los estudios de doctorado.

Desde luego, las vías y pasarelas para combinar estas opciones básicas de didáctica de los idiomas en primaria y secundaria, o de 
Avanzar en la práctica de la docencia: reflexión sobre un itinerario intelectual

I. Vázquez de CAstro especialización disciplinaria para preparar a los estudiantes con contenidos específicamente hispanos, son múltiples. Lo que conviene destacar en el presente caso es que el hispanismo francés ha buscado la difusión de las investigaciones más prestigiosas y recientes por medio de unas oposiciones que tenían o tienen como objetivo institucional la selección de los candidatos más idóneos para los puestos de profesores de español que se proponen en la enseñanza pública y privada concertada en un ámbito nacional.

Tras esta formación de excelencia en el campo de estudio del hispanismo, (en principio, durante la Licenciatura y la preparación de las oposiciones) queda por desarrollar la reflexión sobre cómo transmitir de manera adecuada estos saberes a alumnos, niños o jóvenes en un medio escolar, que no se proponen en principio ser especialistas de la lengua y cultura, sino tener acceso a través de la LVE (Langue Vivante Etrangère) a una disciplina escolar formativa. La brevedad del periodo de prácticas y las dificultades para integrarlas en la formación y la reducidísima parte que ocupan los saberes didácticos o pedagógicos en el currículo de los docentes a menudo llega tarde y dificulta la entrada en la profesión de manera armoniosa y clara. Sin embargo, la evaluación de la competencia docente culmina este proceso de excelencia. Las correspondientes aspiraciones educativas que determinan una didáctica del idioma adaptada a un grupo escolar heterogéneo y no siempre motivado hacen que el aprendizaje del español no haya sido siempre tan eficaz desde el punto de vista lingüístico como sería deseable, pero que se integre en un marco institucional dirigido a nivel de la Academia, que en última instancia emplea al profesor, y de la Educación Nacional que a través de los programas orienta los contenidos a impartir.

Si no siempre se garantiza la excelencia en el idioma, sí es extraordinaria y asombrosa la difusión y adopción del español como segundo idioma aprendido en Francia, ya que es elegido por más de dos tercios de los estudiantes de secundaria del sistema público general y con cifras semejantes en la enseñanza privada. Este éxito merece ser tomado en consideración, así como las posibles disfunciones pedagógicas que se pueden producir en una misma formación propuesta a tantos alumnos con capacidades, representaciones y prácticas extra-escolares muy diversas. A pesar de ellas, la percepción del español como una lengua fácil, atractiva y que puede contribuir al éxito académico de los alumnos parece predominar. Muchas bazas positivas de esta buena imagen vienen del entusiasmo de los hispanistas por la lengua y cultura que enseñan 
Avanzar en la práctica de la docencia: reflexión sobre un itinerario intelectual

I. Vázquez de Castro y por una metodología que ha sido pionera en la introducción de contenidos culturales auténticos desde las primeras lecciones. A través de documentos diversificados como pueden ser textos de autores literarios, fotografías, cuadros, canciones, campañas de sensibilización a diversos temas sociales... se introduce una reflexión sobre la alteridad y lo que aprendemos de su comprensión en la enseñanza lingüística. Y esto se produce desde su introducción en el sistema educativo francés allá por los años 20, en un esfuerzo de difundir una cultura humanista y de paz.

También es interesante reflexionar sobre la interculturalidad franco-española en el campo del hispanismo, considerando con detalle los temas más atractivos para el hispanismo francés: qué centros de interés comparten con lo que estudian, qué aportes suponen para su propia cultura comparándola por similitud o por contraste con la cultura estudiada, cuál ha sido la focalización o punto de vista adoptado en el estudio de un determinado tema, qué convergencias o disparidades metodológicas aparecen en el tratamiento de diversos objetos de estudio. Por todas estas razones de estrecha interculturalidad franco-española me interesé por los orígenes de esta práctica, tanto más que la enseñanza del francés en España se va haciendo cada vez más excepcional y que los acuerdos bilaterales de intercambios entre los dos países escasean. Por ello, la reciprocidad no parecía ser el principal argumento del éxito de la enseñanza del español en Francia.

Aun antes de empezar mi investigación yo ya intuía que al menos un núcleo importante del hispanismo francés había contribuido eficazmente al éxito del español en la enseñanza secundaria. Pero he intentado buscar los elementos que permitan sustentar esta idea inicial. El periodo de entre guerras, durante el primer cuarto del siglo XX, con sus promesas de humanismo en relación con su creencia en el progreso y la ciencia, fue particularmente rico en el establecimiento de lazos de estima y valoración mutua entre filólogos de ambos países. Es de notar la calidad de los trabajos emprendidos, enriquecidos a través de un diálogo permanente entre culturas. Si la enseñanza del español sirvió, en un primer momento, para minorar la enseñanza del alemán en Francia tras la guerra de 1914-1918, las expectativas de sus impulsores se vieron superadas, pues sustituyó también, con los años, al latín y al griego como disciplina formadora del espíritu. Poco a poco el español ocupó un espacio importante en la enseñanza de las artes y en el descubrimiento de realidades extra-nacionales con fines educativos. Tal vez una de las razones de este éxito puede ser el alto contenido artístico y cultural de 
Avanzar en la práctica de la docencia: reflexión sobre un itinerario intelectual

I. Vázquez de Castro los soportes didácticos presentados, así como la metodología activa para explotarlos. Sin embargo, no siempre todo fue tan fácil ni tan positivo: no todos los docentes han conseguido aportar la emoción estética y el deseo de formular una expresión trabajada e interesante sobre objetos culturales densos. A veces la enseñanza del idioma se reduce a memorizar modelos de explicación o del comentario de un documento presentado en clase. Estos trabajos son hechos por el profesor sin que el alumno pueda apropiarse ni el método ni los contenidos necesarios para desarrollar esta tarea. El trabajo tiene una finalidad de obtención de buenas notas y estrategia de selección favorable en el marco escolar más que de verdadero aprendizaje en autonomía de la lengua.

A pesar del efecto bachotage, de las desviaciones e insuficiencias del sistema de estudios con un programa dado, la enseñanza del español en Francia tiene unas señas de identidad pedagógica más amables. Es una de las disciplinas con mayor implicación por parte de los docentes y de los alumnos, presenta un sello particular. A esto contribuye probablemente, por una parte, la riqueza y diversidad cultural del mundo hispánico y su dinamismo; pero, por otra, seguramente también a la proximidad en el momento de su creación como disciplina del mundo de los hispanistas franceses con los miembros de la Institución Libre de Enseñanza y otras entidades afines, primero en España y luego en el exilio. Entonces la Institución era pionera en prácticas pedagógicas innovadoras que la enseñanza del español ha recogido. Entre ellas está la ausencia de un manual o libro de texto y el trabajo de la lengua sobre documentos auténticos, elegidos con sabiduría y cuidado por los docentes. Las experiencias de excursiones o visitas a museos con fines educativos fue una de las características de la Institución Libre de Enseñanza.

Si actualmente esta opción de enriquecimiento cultural a través de la experiencia estética no corresponde siempre con los requisitos del Marco Común de Referencia, sí podemos decir que ha influido la enseñanza de la lengua en Francia por una didáctica de acceso directo a elementos culturales auténticos y significativos. La utilización de recursos tomados de la tradición oral, de canciones actuales o clásicas de gran difusión, de obras de arte plásticas, de poemas o de extractos literarios en una proporción importante han contribuido poderosamente al atractivo de la disciplina. Aun cuando el viaje escolar no es siempre posible y los intercambios se han vuelto casi excepcionales, éstas son a su vez experiencias de exposición protegida a la alteridad. 
Avanzar en la práctica de la docencia: reflexión sobre un itinerario intelectual

I. Vázquez de Castro

INVESTIGACIÓN
SOBRE TEMAS
EDUCATIVOS
EDUCATIVOS

Aunque muchas y numerosas innovaciones actuales de enseñanza de idiomas a nivel europeo o internacional merezcan mi atención, ya sea a través de programas como Apprendre par les langues, por medio de asociaciones como IDEA (International Drama Education Association) o bien por contactos prolongados con organizaciones institucionales como el CIEP (Francia) o el Centro Europeo de Lenguas de Graz (Austria), sin olvidar la experiencia con Glottodrama en Italia donde recibí una formación práctica de enseñanza de idiomas a través del teatro en 2013, preferí orientar mi investigación original en un tema de historia de la educación en España. No es solo un homenaje a figuras injustamente olvidadas sino también una manera de aportar un mayor peso específico de la investigación en otras lenguas europeas como el español, a menudo poco considerada en estos centros internacionales, donde el inglés, el alemán y el francés son lenguas de trabajo. Tampoco he centrado mis esfuerzos en la enseñanza del español en el mundo a través del Instituto Cervantes o de otros centros de formación prestigiosos o eficaces. Sin embargo, consciente de los cambios acelerados experimentados en una didáctica de los idiomas renovada, me he inscrito en el seminario REDESC de la Universidad de Paris-Ouest Nanterre La Défense, dirigido por Mercé Pujol. Con gran generosidad, además de mejorar mis conocimientos en lingüística y socio-lingüística, aceptó acompañar mis esfuerzos de estudio biográfico que desbordaba los temas estrictamente lingüísticos o didácticos. Por ello participó activamente en la presentación de mi trabajo inédito: un estudio biográfico de José Ontañón y Valiente.

Si este estudio había tenido su origen como una investigación de primera mano sobre el exilio en Francia de José Ontañón y la influencia de los demás miembros de la Institución Libre de Enseñanza en los numerosos maestros y profesores exiliados en el hispanismo francés, el trabajo pronto desbordó su objeto inicial a través de una investigación sistemática de la obra de traducción, a menudo reeditada, y de difusión en España de una cultura internacional científica y pedagógica. El estudio sistemático del Boletín de la Institución Libre de Enseñanza y la lectura de libros de memorias en los que se cita a José Ontañón y Valiente nos dibujan al personaje con una presencia permanente y decisiva en la etapa final de la labor de la Institución en España: creación de la Fundación Francisco Giner de los Ríos, gestión y administración del Boletín, redacción de la sección Revista de Revistas así como la firma conjunta con su amigo José Giner Pantoja de los relatos de las excursiones, realizadas en los años 20 y relatadas en 
Avanzar en la práctica de la docencia: reflexión sobre un itinerario intelectual

I. Vázquez de Castro los 30. Esta importante labor intelectual, de gestión y de dirección se acompañó de una constante implicación personal en las tareas docentes, enseñando diversas disciplinas de letras (principalmente latín e idiomas) y de ciencias (física y química, matemáticas, tecnología...) a todos los niveles y a través de experiencias preparadas a conciencia en su vertiente didáctica, adaptadas a cada edad. Y lo que es aún más memorable entre sus alumnos, las actividades deportivas (fútbol, esquí, marcha en montaña, frontón o rounders) o recreativas, organizando juegos colectivos en excursiones y colonias.

Ya en el exilio, José Ontañón y Valiente y su viejo amigo José Giner Pantoja continuaron las actividades culturales colectivas en París, descubriendo el rico patrimonio Francés y visitando las obras de arte hispano conservadas en diversos museos. Era una de las actividades de encuentro de los muchos exiliados que trataban de reagruparse después de la Liberación y que publicaron durante cuatro años un Boletín de la Asociación de Intelectuales Españoles. La muerte de José Ontañón en el verano de 1948 por enfermedad, tras haber logrado obtener un prestigioso puesto de director de los servicios de traducción de la UNESCO y haber contribuido eficazmente a la Sesión llevada a cabo en México el año anterior, cerró esta estrecha colaboración. A través de documentos muy diversos como el discurso fúnebre pronunciado por su amigo José Giner y difundido en Francia y confidencialmente en España, su currículo manuscrito presentado en la UNESCO así como su carta de recomendación sin reservas firmada por Marcel Bataillon, junto con su correspondencia personal conservada en el Collège de France; algunas notas sobre la labor de la UNESCO con recuerdos en verso y prosa tras su muerte en el último número del citado Boletín de los exiliados o su Expediente de depuración del año 1945, conservado en el Archivo de la Memoria Histórica de Salamanca, han constituido la base documental de un estudio biográfico que me ha enseñado mucho sobre la educación después de la Segunda Guerra Mundial y sobre el exilio español en Francia.

La tolerancia, la adaptabilidad y la vida en una sociedad diversa y plural se van a ver muy mejoradas desde entonces por este tipo de proyecto educativo a nivel mundial, que va a permitir una evolución muy positiva para el alumnado, con la proclamación y extensión del derecho a la educación de todo ser humano sin diferencias de género, de origen o de religión. La apertura cognitiva y personal a un mundo multicultural y plurilingüe es un reto educativo todavía pendiente y el desarrollo de las competencias que 
Avanzar en la práctica de la docencia: reflexión sobre un itinerario intelectual

I. Vázquez de Castro permiten estas interacciones positivas entre las personas son cada vez más necesarias en toda Europa y en el conjunto del planeta. A ello contribuyeron sin duda unos exiliados que habiendo perdido "todo lo que era suyo y resultó ser nada" conservaron sus ideas pedagógicas y su palabra transmisora de una cultura original particularmente interesante desde el punto educativo. 